\title{
Capacity of the Pectoralis Major Muscle May Be a Prognostic Factor for Aspiration Pneumonia
}

\author{
Kumiko Sakaguchi ${ }^{*}$, Shuichi Hara ${ }^{2}$ \\ ${ }^{1}$ Department of Rehabilitation, Kagoshima Red-Cross Hospital, Kagoshima, Japan \\ ${ }^{2}$ School of Health Science, Kyusyu University of Health and Welfare, Miyazaki, Japan \\ Email: ^kmksakaguchi@gmail.com
}

How to cite this paper: Sakaguchi, K. and Hara, S. (2017) Capacity of the Pectoralis Major Muscle May Be a Prognostic Factor for Aspiration Pneumonia. Advances in Aging Research, 6, 101-117. https://doi.org/10.4236/aar.2017.66011

Received: October 11, 2017

Accepted: November 27, 2017

Published: November 30, 2017

Copyright ( 92017 by authors and Scientific Research Publishing Inc. This work is licensed under the Creative Commons Attribution International License (CC BY 4.0).

http://creativecommons.org/licenses/by/4.0/

(c) (i) Open Access

\begin{abstract}
Objective: Aspiration pneumonia is thought to be caused by a decline in respiratory and swallowing function. We aimed to clarify whether the pectoralis major muscle and the rectus abdominis muscles are prognostic factors for aspiration pneumonia and to investigate the relationships between these muscles and nutritional status, swallowing function and sarcopenia, Methods: Medical records of 139 Japanese patients hospitalized for aspiration pneumonia between December 2010 and December 2014 were reviewed retrospectively. The volume and thickness of the pectoralis major muscle, the crosssectional area and thickness of the rectus abdominis muscles, and cross-sectional area of the psoas major muscle were measured using computed tomography. Swallowing function, nutritional status, activities of daily living, and prognosis also were evaluated. Results: The volume [Median: (left) 4713.2 $\mathrm{mm}^{3}$ vs. $4232.6 \mathrm{~mm}^{3}$ (right) $4981.7 \mathrm{~mm}^{3}$ vs. $\left.4362.6 \mathrm{~mm}^{3} \mathrm{p}<0.05\right]$ and thickness [Median: (left) $6.9 \mathrm{~mm}$ vs. $4.6 \mathrm{~mm}$ (right) $7.3 \mathrm{~mm}$ vs. $5.7 \mathrm{~mm} \mathrm{p}<0.01$ ] of the pectoralis major muscle and thickness of the right rectus abdominis muscles [Median: $7.3 \mathrm{~mm}$ vs. $5.8 \mathrm{~mm} \mathrm{p}<0.05$ ] were significantly larger, while Mini-Nutritional Assessment Short Form (MNA-SF) [Median: 6.0 vs. $4.0 \mathrm{p}<$ 0.01] and Functional Oral Intake Scale (FOIS) [Median: 3 vs. $1 \mathrm{p}<0.01$ ] scores were significantly higher in patients who survived. The volume [Median: (left) $5789.1 \mathrm{~mm}^{3}$ vs. $3706.5 \mathrm{~mm}^{3}$ (right) $5650.3 \mathrm{~mm}^{3}$ vs. $4003.7 \mathrm{~mm}^{3} \mathrm{p}<$ 0.01] and thickness [Median: (left) $7.1 \mathrm{~mm}$ vs. $5.9 \mathrm{~mm} \mathrm{p}<0.05$ ] of the pectoralis major muscle and cross-sectional area of the psoas major muscle (left and right) [Median: (left) $500.1 \mathrm{~mm}^{2}$ vs. $432.0 \mathrm{~mm}^{2}$ (right) $563.5 \mathrm{~mm}^{2}$ vs. $446.3 \mathrm{~mm}^{2} \mathrm{p}<0.01$ ] were significantly larger, while albumin levels [Median: $3.8 \mathrm{~g} / \mathrm{dl}$ vs. $3.4 \mathrm{~g} / \mathrm{dl} \mathrm{p}<0.01$ ] and MNA-SF [Median: 6.0 vs. $5.0 \mathrm{p}<0.01$ ] and FOIS [Median: 4 vs. $1 \mathrm{p}<0.01$ ] scores were significantly higher in patients with coexisting diseases. Conclusion: The capacity of the pectoralis major muscle may be an independent factor in the prognosis of elderly patients with
\end{abstract}


aspiration pneumonia as a primary disease.

\section{Keywords}

Aspiration Pneumonia, Prognosis, Elderly, Nutritional Status, Pectoralis Major Muscle

\section{Introduction}

Aspiration pneumonia is a cause of death in the elderly, and an important reason behind patients bedridden. Dysphagia is a cause of aspiration pneumonia, and can affect sarcopenia in the elderly. Sarcopenia is narrowly defined as the loss of muscle mass with aging, and more broadly as a loss of muscle mass with aging, activity, nutrition, and disease [1] [2] [3] [4]. This reduction of muscle mass occurs systemically, including the respiratory muscles [5]-[11]. Aspiration pneumonia is thought to be caused by a decline in respiratory and swallowing functions. In the process of aspiration, coughing acts as a preventative function by expectorating irritants from the surface of the trachea. Coughing is also involved in the maintenance of respiratory function. Hence, healthy respiratory muscles may provide protection against aspiration pneumonia.

Many previous studies have suggested a relationship between the area of the psoas major muscle and prognosis in patients with malignant tumors [12] [13] [14] [15]. These studies suggest that muscle mass may be a prognostic factor in certain diseases. The respiratory muscles include the diaphragm, intercostal muscle, the rectus abdominis muscle, oblique muscle group, and others. Many of these muscles have small capacity, which may vary considerably due to the slice planes of their positions. In this study, we evaluated the respiratory muscles using chest and abdominal computed tomography (CT), and examined their relationship with prognosis in elderly patients with aspiration pneumonia. The pectoralis major muscle and rectus abdominis muscle, which are easily identified on chest and abdominal CT, were targeted. Furthermore, the area of the psoas major muscle was measured, as it has been used as a prognostic factor in previous studies investigating patients with aspiration pneumonia.

The purpose of this study was to clarify whether the pectoralis major muscle and rectus abdominis muscle are prognostic factors for aspiration pneumonia and to investigate the relationships between these muscles and nutritional status, swallowing function, and sarcopenia, Furthermore, we examined the difference in prognosis between patients with aspiration pneumonia as a primary or coexisting disease.

\section{Methods}

\subsection{Subjects}

The medical records of 138 patients living in Japan and hospitalized for aspira- 
tion pneumonia at Kagoshima Red Cross Hospital from December 2010 to December 2014 were reviewed retrospectively. It was excludes that who didn't perform a chest to abdominal Computed tomography (CT) and/or who didn't measure the albumin levels. Seventy-one patients had aspiration pneumonia as a primary disease while 67 patients had aspiration pneumonia during treatment for other diseases (except for one who died due to deterioration of the original disease).

\subsection{Muscle Measurements}

CT (Toshiba Co., Ltd.; Aquilion) was used to calculate the volume and thickness of each muscle. The CT images were manipulated on a picture archiving and communication system (AstroStage Co., Ltd.; Nazca), and area was measured by tracing each contour of the muscle as a region of interest (ROI). The origin of the pectoralis major muscle was the anterior surface of the medial half of the clavicle, sternum, anterior surface of the rib cartilage (second to seventh ribs), and rectus sheath. Therefore, the volume of the pectoralis major muscle was measured using a cross-sectional area from the clavicle to the seventh costal cartilage, and the sum of the cross-sectional areas and slice width were calculated as the assessed value (Figure 1(a), Figure 1(b)).

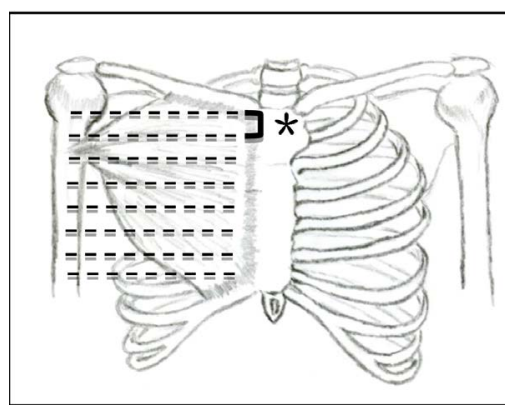

(a)

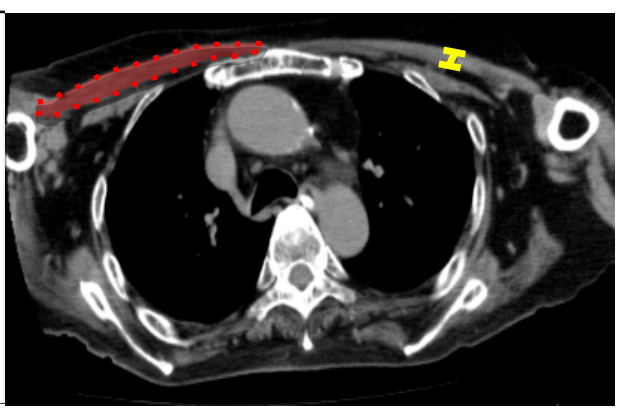

(b)

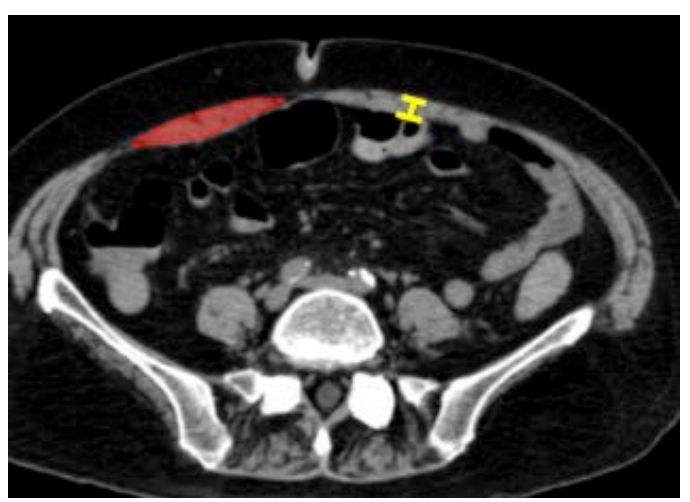

(c)

Figure 1. Method for measuring the capacity of the pectoralis major muscle and rectus abdominis muscle. (a) Method for measuring the volume of pectoralis major muscle $\left({ }^{*}: 6\right.$ $\mathrm{mm}$ ); (b) Method for measuring the volume and the thickness of pectoralis major muscle; (c) Method for measuring the cross-sectional area and the thickness of rectus abdominis muscle. 
Thickness of the pectoralis major muscle was measured at the largest part of the bronchus (Figure 1(b)). Cross-sectional area and thickness of the rectus abdominis muscle were measured on abdominal CT images at the level of the navel (Figure 1(c)). The cross-sectional area was calculated by tracing the contour of the right and left rectus abdominis muscle as the ROI, while thickness was measured at the maximum width. The cross-sectional area of the psoas major muscle was measured on transverse CT images at the iliac crest level (Figure 2). All measurements of the pectoralis major muscle, rectus abdominis muscle, and psoas major muscle were performed on the left and right sides.

\subsection{Nutritional Status}

Albumin levels were assessed from patients' serum. The Mini-Nutritional Assessment Short Form (MNA-SF) [16] [17] [18] questionnaire was administered to evaluate subjective and objective nutritional status. From the 6 evaluation items (food intake, weight loss, mobility, acute disease, psychiatric disorder, and body mass index [BMI]), the nutritional status was evaluated using a 14-point scale as follows: 12 to 14 points, good nutritional status; 8 to 11 points, low risk of nutritional status (at risk); and 0 to 7 points, low nutritional status.

\subsection{Swallowing Function}

The swallowing function was evaluated using the Functional Oral Intake Scale (FOIS) [19]. The FOIS is graded as follows: level 7, total oral diet with no restrictions; level 6, total oral diet with multiple consistencies without special preparation, but with specific food limitations; level 5 , total oral diet with multiple consistencies, but requiring special preparation or compensations; level 4, total oral diet of a single consistency; level 3, tube dependent with consistent oral intake of food or liquid; level 2, tube dependent with minimal attempts of food or liquid; and level 1 , no oral intake.

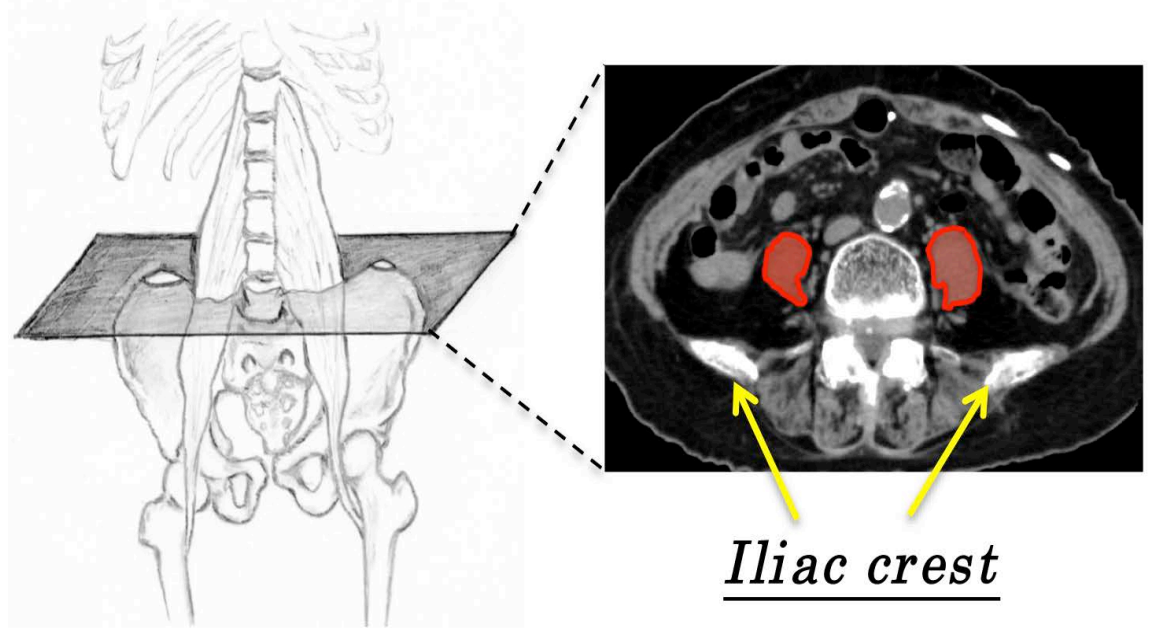

Figure 2. Method for measuring the cross-sectional area of the psoas major muscle. 


\subsection{Activities of Daily Living}

Activities of daily living were evaluated at admission using the Barthel Index (BI) [20]. The BI determines the independent level of activities of daily living from 10 items, including feeding, grooming, bathing, dressing, bowel and bladder care, and toilet use.

\subsection{Prognosis}

Primary disease, medical history, number of hospitalization, and the prognosis at the time of hospital discharge were investigated from patients' medical records.

\subsection{Statistical Analysis}

All statistical analyses were performed using SPSS version 23 (IBM Corporation).

\section{1) All subjects}

The associations between volume and thickness of the pectoralis major muscle, cross-sectional area and thickness of the rectus abdominis muscle, cross-sectional area of the psoas major muscle, albumin levels, MNA-SF score, FOIS score, BI score, age, gender, number of days of hospitalization, and prognosis were analyzed using Spearman's rank correlation coefficients. The Mann-Whitney $U$ test was used to analyze differences in the above variables between patients grouped based on survival or death.

2) Primary versus coexisting disease

The Mann-Whitney $U$ test was used to perform 2 comparisons: 1) patients with aspiration pneumonia as a primary versus coexisting disease, and 2) patients who survived versus patients who died within each primary and coexisting disease group. In addition, based on the history of cerebrovascular disease in the primary disease group, comparisons were made between patients who survived and those who died. Coexisting disease groups included a cerebrovascular disease group, an orthopedic disease group, an internal disease group by original disease, a cerebrovascular disease group, and an internal disease group were compared for survival and death. For the orthopedic disease group is one subject died so statistical analysis was not performed. The volume and thickness of the pectoralis major muscle, cross-sectional area and the thickness of the rectus abdominis muscle, cross-sectional area of the psoas major muscle, albumin levels, MNA-SF score, FOIS score, BI score, age, gender, and number of days of the hospitalization were compared between groups. In forced entry multiple regression analysis in each group, the dependent variable was defined as prognosis, while the independent variables were defined as those with a significant difference in the group comparison.

\subsection{Ethics}

Since this study is a retrospective study using medical record information, it 
represents a case of the provision of existing specimens as outlined in the "Ethical Guidelines for Medical and Health Research Involving Human Subjects (Ministry of Health, Labor and Welfare and Ministry of Education, Culture, Sports, Science and Technology in Japan). In accordance with Chapter 12 of the "Ethical Guidelines for Medical and Health Research Involving Human Subjects", informed consent procedures were waivered. The present study was approved by the Ethics Committee of Kagoshima Red Cross Hospital and performed according to the ethical guidelines of the Declaration of Helsinki.

\section{Results}

\subsection{Baseline Characteristics}

Table 1 shows the patients' baseline characteristics. The median age was 84 years (range, 78 - 88 years). The median volume of the pectoralis major muscle was $4529.5 \mathrm{~mm}^{3}$ (range, $3146.2-7410.3 \mathrm{~mm}^{3}$ ) on the left and $4679.0 \mathrm{~mm}^{3}(3172.2$ $7004.15 \mathrm{~mm}^{3}$ ) on the right. The median thickness of the pectoralis major muscle was $6.6 \mathrm{~mm}$ (range, $4.7-8.8 \mathrm{~mm}$ ) on the left and $7.0 \mathrm{~mm}$ (range, $5.1-8.9 \mathrm{~mm}$ ) on the right. The median cross-sectional area of the rectus abdominis muscle was $222.8 \mathrm{~mm}^{2}$ (range, $142.2-325.0 \mathrm{~mm}^{2}$ ) on the left and $219.3 \mathrm{~mm}^{2}$ (range, $132.0-346.6 \mathrm{~mm}^{2}$ ) on the right. The median thickness of the rectus abdominis muscle was $5.9 \mathrm{~mm}$ (range, $4.7-8.4 \mathrm{~mm}$ ) on the left and $6.7 \mathrm{~mm}$ (range, 4.3 - 8.7 $\mathrm{mm}$ ) on the right.

Table 1. Baseline characteristics $(n=138)$.

\begin{tabular}{|c|c|c|c|}
\hline & \multicolumn{3}{|c|}{ Median (Interquartile range) } \\
\hline & All $(\mathrm{n}=138)$ & Primary $(\mathrm{n}=71)$ & Coexisting $(n=67)$ \\
\hline Age $(y r)$ & $84.5(78.0-88.0)$ & $87.0(82.0-90.0)$ & $81.0(74.0-86.0)$ \\
\hline Volume of left pectoralis majormuscle $\left(\mathrm{mm}^{3}\right)$ & $4555.9(3103.1-7487.7)$ & $3706.5(2665.0-5716.2)$ & $5789.1(4047.9-8952.1)$ \\
\hline Volume of right pectoralis majormuscle $\left(\mathrm{mm}^{3}\right)$ & $4704.5(3148.4-7009.3)$ & $4003.8(2512.1-5935.1)$ & $5650.3(4132.4-8294.1)$ \\
\hline Thickness of left pectoralis major muscle (mm) & $6.6(4.6-8.8)$ & $5.9(4.0-8.8)$ & $7.1(5.4-9.1)$ \\
\hline Thickness of right pectoralis major muscle (mm) & $6.9(5.1-8.9)$ & $6.7(4.9-8.8)$ & $7.7(5.5-9.5)$ \\
\hline Cross - sectional area of left rectus abdominis muscle $\left(\mathrm{mm}^{2}\right)$ & $222.7(142.2-325.0)$ & $216.2(133.0-326.7)$ & $229.1(148.7-336.1)$ \\
\hline Cross - sectional area of right rectus abdominis muscle $\left(\mathrm{mm}^{2}\right)$ & $219.3(131.8-346.5)$ & $201.8(121.1-333.5)$ & $242.0(153.7-365.0)$ \\
\hline Thickness of left rectus abdominismuscle (mm) & $5.8(4.7-8.4)$ & $6.0(4.6-8.3)$ & $5.9(4.9-9.2)$ \\
\hline Thickness of right rectus abdominis muscle (mm) & $6.7(4.7-8.7)$ & $7.0(4.6-8.7)$ & $6.6(5.2-8.6)$ \\
\hline Cross - sectional area of left psoas major muscle $\left(\mathrm{mm}^{2}\right)$ & $453.5(317.8-593.7)$ & $432.0(305.1-523.0)$ & $500.1(350.8-732.3)$ \\
\hline Cross - sectional area of right psoasmajor muscle $\left(\mathrm{mm}^{2}\right)$ & $496.6(376.0-618.0)$ & $446.3(316.5-566.4)$ & $564.8(458.7-685.2)$ \\
\hline Albumin level (g/dL) & $3.5(2.8-4.1)$ & $3.4(2.8-3.7)$ & $3.7(3.1-4.2)$ \\
\hline MNA-SF score & $5.0(4.0-7.0)$ & $3.0(4.0-6.0)$ & $6.0(5.0-8.0)$ \\
\hline FOIS score & $1.0(1.0-4.0)$ & $1.0(1.0-4.0)$ & $4.0(1.0-5.0)$ \\
\hline BI score & $0.0(0.0-0.0)$ & $0.0(0.0-0.0)$ & $0.0(0.0-0.0)$ \\
\hline Hospitalized days (day) & $34.0(18.0-60.0)$ & $26.0(13.0-50.0)$ & $44.0(27.0-75.0)$ \\
\hline
\end{tabular}


In the primary disease group, the median age was 87 years (range, $82-90$ years). The median volume of the pectoralis major muscle was $3706.5 \mathrm{~mm}^{3}$ (range, $2665.0-5716.18 \mathrm{~mm}^{3}$ ) on the left and $4003.7 \mathrm{~mm}^{3}$ (range, 2512.1 $5935.1 \mathrm{~mm}^{3}$ ) on the right. The median thickness of the pectoralis major muscle was $5.9 \mathrm{~mm}$ (range, $4.0-8.8 \mathrm{~mm}$ ) on the left and $6.7 \mathrm{~mm}$ (range, $4.9-8.8 \mathrm{~mm}$ ) on the right. The median cross-sectional area of the rectus abdominis muscle was $216.3 \mathrm{~mm}^{2}$ (range, $133.0-326.7 \mathrm{~mm}^{2}$ ) on the left and $201.8 \mathrm{~mm}^{2}$ (range, $121.1-333.5 \mathrm{~mm}^{2}$ ) on the right. The median thickness of the rectus abdominis muscle was $6.0 \mathrm{~mm}$ (range, $4.6-8.3 \mathrm{~mm}$ ) on the left and $7.0 \mathrm{~mm}$ (range, 4.6 - 8.7 $\mathrm{mm}$ ) on the right. In the primary disease group, 47 subjects had a history of cerebrovascular disease (Figure 3(a)).

In the coexisting disease group, the median age was 81 years (range, 74.5 - 86 years). The median volume of the pectoralis major muscle was $5700.4 \mathrm{~mm}^{3}$ (range, $4067.1-8751.8 \mathrm{~mm}^{3}$ ) on the left and $5583.0 \mathrm{~mm}^{3}$ (range, $4144.6-8287.6$ $\mathrm{mm}^{3}$ ) on the right. The median the thickness of pectoralis major muscle was 7.1 $\mathrm{mm}$ (range, $5.3-9.0 \mathrm{~mm}$ ) on the left and $7.7 \mathrm{~mm}$ (range, $5.5-9.4 \mathrm{~mm}$ ) on the right. The median cross-sectional area of the rectus abdominis muscle was 229.1 $\mathrm{mm}^{2}$ (range, $148.8-336.1 \mathrm{~mm}^{2}$ ) on the left and $242.1 \mathrm{~mm}^{2}$ (range, $152.7-364.1$ $\mathrm{mm}^{2}$ ) on the right. The median thickness of the rectus abdominis muscle was 5.9 $\mathrm{mm}$ (range, $5.0-9.2 \mathrm{~mm}$ ) on the left and $6.7 \mathrm{~mm}$ (range, $5.3-8.7 \mathrm{~mm}$ ) on the right. The original diseases in the coexisting disease group included 41 cerebrovascular diseases, 12 orthopedic diseases, and 14 internal diseases (Figure 3(b)).

\subsection{All Subjects}

1) Correlation coefficients

Table 2 shows the correlation coefficients of the variables. Prognosis was significantly correlated with volume and thickness of the pectoralis major muscle (left and right), cross-sectional area of the right rectus abdominis muscles,
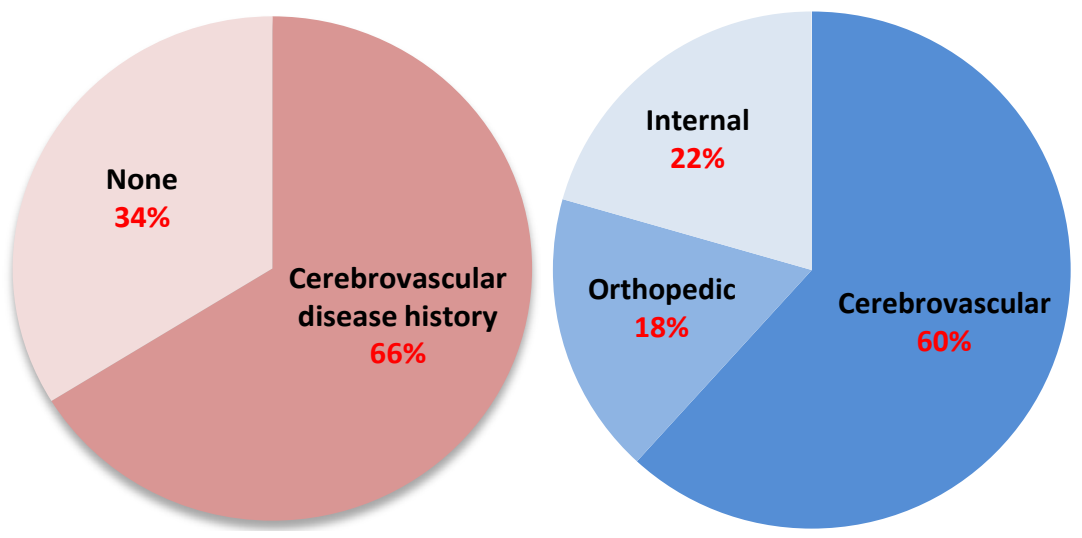

Figure 3. Disease rates in each group (primary/coexisting). (a) Classification based on history of cerebrovascular disease in the primary disease group [Cerebrovascular disease historygroup ( $\mathrm{n}=47$ ) vs. None group $(\mathrm{n}=24)$ ]; (b) Classification by the disease that resulted in hospitalization in the coexisting disease group [Cerebrovascular diseasegroup ( $\mathrm{n}$ $=40)$ vs. Orthopedic disease group $(\mathrm{n}=12)$ vs. Internal disease group $(\mathrm{n}=14)]$. 
Table 2. Results of the Spearman rank correlation tests.

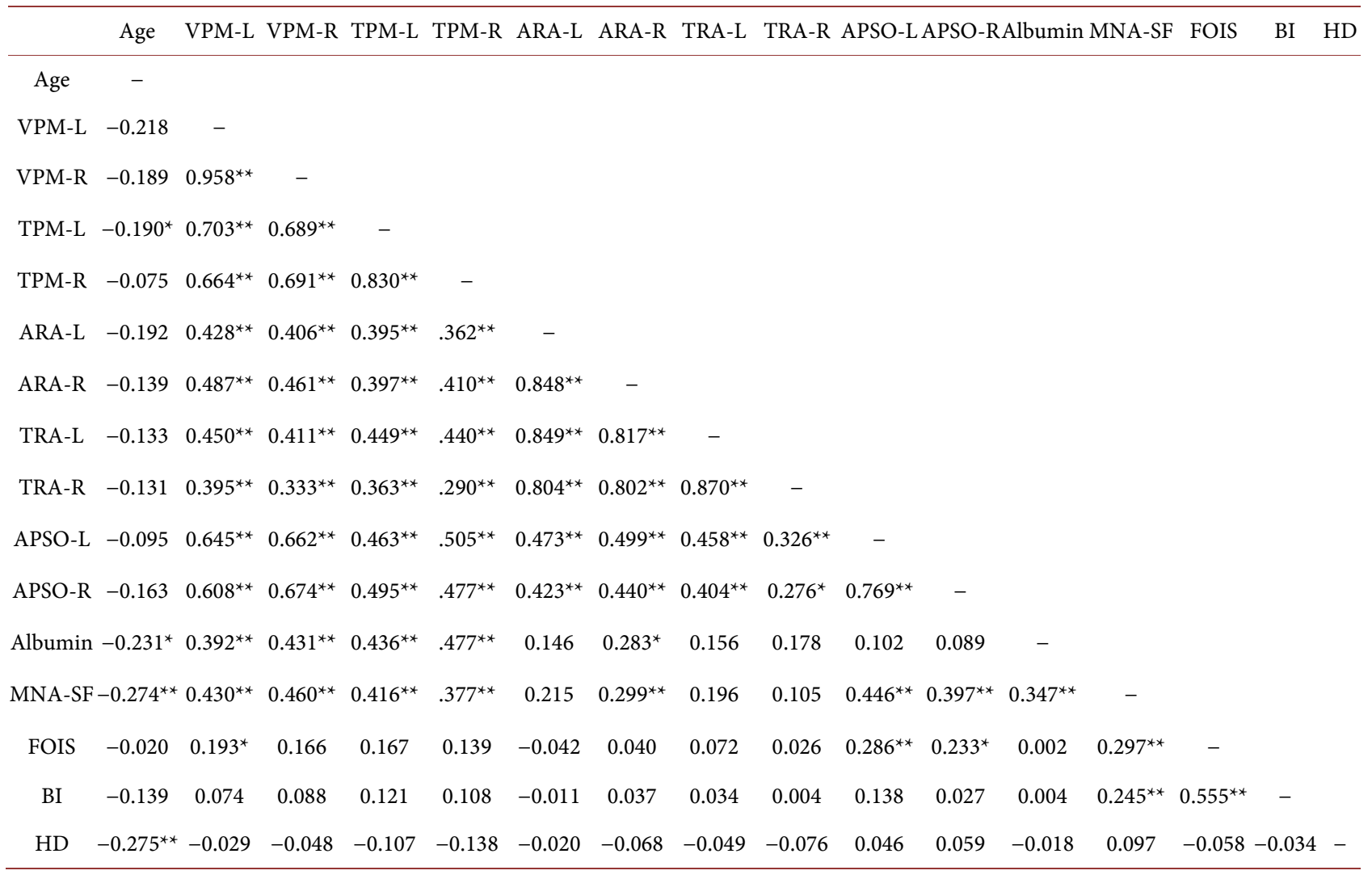

VPM: Volume of pectoralis major muscle, TPM: Thickness of pectoralis major muscle, ARA: Cross-sectional area of rectus abdominis muscle, TRA: Thickness of rectus abdominis muscle; APSO: Cross-sectional area of psoas major muscle, ND: Hospitalized days ${ }^{* *} \mathrm{p}<0.01,{ }^{*} \mathrm{p}<0.05$.

thickness of the rectus abdominis muscle (left and right), MNA-SF score, albumin levels, gender, and number of days of hospitalization. Both the volume and thickness of the pectoralis major muscle (left and right) were significantly correlated with the cross-sectional area and thickness of the rectus abdominis muscle (left and right), cross-sectional area of the psoas major muscle (left and right), MNA-SF score, and albumin levels. Both the cross-sectional area and thickness of the rectus abdominis muscle (left and right) were significantly correlated with the volume and thickness of the pectoralis major muscle (left and right), and cross-sectional area of the psoas major muscle (left and right). The cross-sectional area of the psoas major muscle (left and right) was significantly correlated with the volume and thickness of the pectoralis major muscle (left and right), cross-sectional area and thickness of the rectus abdominis muscle (left and right), MNA-SF score, and FOIS score.

\section{2) Prognostic factors}

Table 3 shows the comparisons of variables between the prognosis groups. The volume and thickness of the pectoralis major muscle (left and right) and the thickness of the rectus abdominis muscle were significantly larger, while MNA-SF and FOIS scores were significantly higher in the patients who survived compared to those who did not. 
Table 3. Comparison between prognosis groups.

\begin{tabular}{|c|c|c|}
\hline & $\begin{array}{c}\text { Survival group }(\mathrm{n}=106) \\
\text { Median (Interquartile range) }\end{array}$ & $\begin{array}{c}\text { Death group }(\mathrm{n}=32) \\
\text { Median (Interquartile range) }\end{array}$ \\
\hline Volume of left pectoralis major muscle $\left(\mathrm{mm}^{3}\right)$ & $4713.2(3311.6-7949.1)^{*}$ & $4232.6(2256.2-5632.7)^{*}$ \\
\hline Volume of right pectoralis major muscle $\left(\mathrm{mm}^{3}\right)$ & $4981.7(3391.1-7463.5)^{\star}$ & $4362.6(2331.4-5943.6)^{\star}$ \\
\hline Thickness of left pectoralis major muscle (mm) & $6.9(5.1-9.2)^{\star *}$ & $4.6(3.4-8.1)^{\star \star}$ \\
\hline Thickness of right pectoralis major muscle (mm) & $7.3(5.5-9.7)^{\star *}$ & $5.7(4.3-7.9)^{\star \star}$ \\
\hline Cross-sectional area of left rectus abdominis muscle $\left(\mathrm{mm}^{2}\right)$ & $230.8(151.5-327.8)$ & $199.0(104.8-323.9)$ \\
\hline Cross-sectional area of right rectus abdominis muscle $\left(\mathrm{mm}^{2}\right)$ & $226.2(162.8-353.4)$ & $191.6(78.5-320.8)$ \\
\hline Thickness of left rectus abdominis muscle (mm) & $6.0(5.0-8.9)$ & $4.9(3.9-7.6)$ \\
\hline Thickness of right rectus abdominis muscle (mm) & $7.3(5.4-8.9)^{*}$ & $5.8(4.2-7.3)^{*}$ \\
\hline Cross-sectional area of left psoas major muscle $\left(\mathrm{mm}^{2}\right)$ & $471.9(333.6-616.8)$ & $392.4(285.8-577.7)$ \\
\hline Cross-sectional area of right psoas major muscle $\left(\mathrm{mm}^{2}\right)$ & $517.8(412.7-631.4)$ & $462.1(291.8-602.8)$ \\
\hline Albumin level (g/dl) & $3.7(2.9-4.1)^{* *}$ & $3.1(2.8-3.7)^{\star *}$ \\
\hline MNA-SF score & $6.0(4.0-7.0)^{* *}$ & $4.0(3.0-6.0)^{* \star}$ \\
\hline FOIS score & $3.0(1.0-4.0)^{\star \star}$ & $1.0(1.0-3.0)^{\star *}$ \\
\hline BI score & $0.0(0.0-3.8)$ & $0.0(0.0-0.0)$ \\
\hline Hospitalized days (day) & $34.5(19.0-60.0)$ & $32.0(13.3-67.0)$ \\
\hline Age (yr) & $84.0(76.0-88.0)$ & $85.5(79.5-90.0)$ \\
\hline
\end{tabular}

${ }^{* *} \mathrm{p}<0.01 .{ }^{*} \mathrm{p}<0.05$.

\subsection{Primary versus Coexisting Disease}

1) Comparison between disease groups

Table 4 shows the comparisons of variables between the disease groups. The volume and thickness of the pectoralis major muscle (left and right) and the cross-sectional area of the psoas major muscle (left and right) were significantly larger, while albumin levels, MNA-SF scores, and FOIS scores were significantly higher in the coexisting disease group than in the primary disease group. In addition, the number of days of hospitalization was significantly higher in the coexisting disease group than in the primary disease group.

2) Prognostic factors

Table 5 shows the comparisons of variables between prognosis groups in each disease group, respectively. In the primary disease group, the volume and thickness of the pectoralis major muscle (left and right) were significantly larger, while albumin levels and MNA-SF scores were significantly higher in patients who survived compared to those who died. In the coexisting disease group, the thickness of the left pectoralis major muscle was significantly larger and FOIS scores were significantly higher in patients who survived compared to those who did not.

3) Cerebrovascular disease history in the primary group

Table 6 shows the comparisons of variables between prognosis groups in the 
Table 4. Comparison between disease groups.

\begin{tabular}{ccc}
\hline & $\begin{array}{c}\text { Primary group }(\mathrm{n}=71) \\
\text { Median (Interquartile range) }\end{array}$ & $\begin{array}{c}\text { Coexisting group }(\mathrm{n}=67) \\
\text { Median (Interquartile range) }\end{array}$ \\
\hline Volume of left pectoralis major muscle $\left(\mathrm{mm}^{3}\right)$ & $3706.5(2665.0-5716.2)^{* *}$ & $5789.1(4047.9-8952.1)^{* *}$ \\
Volume of right pectoralis major muscle $\left(\mathrm{mm}^{3}\right)$ & $4003.7(2512.1-5935.1)^{* *}$ & $5650.3(4132.4-8294.1)^{* *}$ \\
Thickness of left pectoralis major muscle $(\mathrm{mm})$ & $5.9(4.0-8.8)^{*}$ & $7.1(5.4-9.1)^{*}$ \\
Thickness of right pectoralis major muscle $(\mathrm{mm})$ & $6.7(4.9-8.8)$ & $7.7(5.5-9.5)$ \\
Cross-sectional area of left rectus abdominis muscle $\left(\mathrm{mm}^{2}\right)$ & $216.3(133.0-326.7)$ & $229.1(148.8-335.2)$ \\
Cross-sectional area of right rectus abdominis muscle $\left(\mathrm{mm}^{2}\right)$ & $201.8(121.1-333.5)$ & $241.9(152.7-364.1)$ \\
Thickness of left rectus abdominis muscle $(\mathrm{mm})$ & $6.0(4.6-8.3)$ & $5.9(5.0-9.2)$ \\
Thickness of right rectus abdominis muscle $\left(\mathrm{mm}^{2}\right)$ & $7.0(4.6-8.7)$ & $6.6(5.2-8.7)$ \\
Cross-sectional area of left psoas major muscle $\left(\mathrm{mm}^{2}\right)$ & $432.0(305.1-523.0)^{* *}$ & $500.1(354.8-732.3)^{* *}$ \\
Cross-sectional area of right psoas major muscle $\left(\mathrm{mm}^{2}\right)$ & $446.3(316.5-566.4)^{* *}$ & $563.5(461.1-695.2)^{* *}$ \\
Albumin level (g/dl) & $3.4(2.8-3.7)^{* *}$ & $3.8(3.1-4.3)^{* *}$ \\
MNA-SF score & $5.0(3.0-6.0)^{* *}$ & $6.0(5.0-8.0)^{* *}$ \\
FOIS score & $1.0(1.0-4.0)^{* *}$ & $4.0(1.0-5.0)^{* *}$ \\
BI score & $0.0(0.0-0.0)$ & $0.0(0.0-0.0)$ \\
Hospitalized days (day) & $26.0(13.0-50.0)^{* *}$ & $44.0(27.0-75.0)^{* *}$ \\
Age (yr) & $87.0(82.0-90.0)^{* *}$ & $81.0(74.0-86.0)^{* *}$ \\
\hline
\end{tabular}

${ }^{* *} \mathrm{p}<0.01 .{ }^{*} \mathrm{p}<0.05$.

Table 5. Comparison between prognosis groups within each group of primary and coexisting.

\begin{tabular}{|c|c|c|c|c|}
\hline & \multicolumn{4}{|c|}{ Median (Interquartile range) } \\
\hline & \multicolumn{2}{|c|}{ Primary group $(\mathrm{n}=71)$} & \multicolumn{2}{|c|}{ Coexisting group $(n=67)$} \\
\hline & Survival group $(\mathrm{n}=53)$ & Death group $(\mathrm{n}=18)$ & Survival group $(\mathrm{n}=53)$ & Death group $(\mathrm{n}=14)$ \\
\hline $\begin{array}{l}\text { Volume of left pectoralis } \\
\text { major muscle }\left(\mathrm{mm}^{3}\right)\end{array}$ & $4210.8(2806.7-6525.7)^{*}$ & $2902.2(1954.2-5100.6)^{*}$ & $6138.4(4051.2-9387.3)$ & $4863.8(3745.2-7873.3)$ \\
\hline $\begin{array}{l}\text { Volume of right pectoralis } \\
\text { major muscle }\left(\mathrm{mm}^{3}\right)\end{array}$ & $4248.6(2759.2-6567.6)^{\star}$ & $3122.1(1894.7-4898.0)^{*}$ & $6529.0(3891.3-8386.8)$ & $5291.8(4061.5-7326.8)$ \\
\hline $\begin{array}{l}\text { Thickness of left pectoralis } \\
\text { major muscle }(\mathrm{mm})\end{array}$ & $6.3(4.7-9.3)^{*}$ & $4.3(3.1-7.8)^{*}$ & $7.6(5.7-8.9)^{\dagger}$ & $5.4(3.4-9.3)^{\dagger}$ \\
\hline $\begin{array}{l}\text { Thickness of right pectoralis } \\
\text { major muscle }(\mathrm{mm})\end{array}$ & $7.0(5.2-9.5)^{\star \star}$ & $5.4(3.8-6.8)^{\star *}$ & $7.8(5.7-9.9)$ & $6.5(3.4-8.9)$ \\
\hline $\begin{array}{l}\text { Cross-sectional area of left } \\
\text { rectusabdominis muscle }\left(\mathrm{mm}^{2}\right)\end{array}$ & $242.5(142.3-354.1)$ & $181.9(50.6-265.5)$ & $222.7(151.5-311.2)$ & $232.0(140.7-360.2)$ \\
\hline $\begin{array}{l}\text { Cross-sectional area of right } \\
\text { rectusabdominis muscle }\left(\mathrm{mm}^{2}\right)\end{array}$ & $213.5(141.9$ - 346.6) & $187.8(73.1-259.8)$ & $242.6(178.8-371.8)$ & $242.0(113.2-362.8)$ \\
\hline $\begin{array}{l}\text { Thickness of left rectus } \\
\text { abdominismuscle (mm) }\end{array}$ & $6.0(4.7-9.3)$ & $4.8(4.0-7.5)$ & $6.1(5.1-9.3)$ & $4.9(3.7-7.6)$ \\
\hline $\begin{array}{l}\text { Thickness of right rectus } \\
\text { abdominismuscle (mm) }\end{array}$ & $7.5(5.5-8.9)$ & $4.7(3.9-8.2)$ & $7.3(5.3-9.6)$ & $6.6(4.3-7.0)$ \\
\hline $\begin{array}{l}\text { Cross-sectional area of left } \\
\text { psoas major muscle }\left(\mathrm{mm}^{2}\right)\end{array}$ & $434.4(306.9-531.8)$ & $358.9(255.3-484.1)$ & $505.9(386.9-752.1)$ & $495.1(305.1-632.4)$ \\
\hline $\begin{array}{l}\text { Cross-sectional area of right } \\
\text { psoas major muscle }\left(\mathrm{mm}^{2}\right)\end{array}$ & $453.2(328.1-567.5)$ & $414.4(292.1-511.4)$ & $578.1(481.0-744.3)$ & $532.3(267.0-651.0)$ \\
\hline Albumin level (g/dl) & $3.6(2.8-3.7)^{\star *}$ & $3.0(2.6-3.3)^{\star *}$ & $3.9(3.1-4.3)$ & $3.5(3.0-4.4)$ \\
\hline MNA-SF score & $5.0(3.0-6.5)^{\star *}$ & $3.5(3.0-5.0)^{\star *}$ & $6.0(5.0-8.0)$ & $6.0(4.0-8.0)$ \\
\hline FOIS score & $1.0(1.0-4.0)$ & $1.0(1.0-3.3)$ & $4.0(1.0-5.0)^{\ddagger}$ & $1.0(1.0-1.8)^{\ddagger}$ \\
\hline BI score & $0.0(0.0-2.5)$ & $0.0(0.0-0.0)$ & $0.0(0.0-5.0)$ & $0.0(0.0-0.0)$ \\
\hline Hospitalized days (day) & $26.0(13.0-46.5)$ & $28.0(10.8-61.0)$ & $45.0(27.5-74.5)$ & $38.0(18.8-87.3)$ \\
\hline Age (yr) & $86.0(82.5-89.0)$ & $88.0(81.8-90.0)$ & $81.0(75.0-86.0)$ & $83.0(73.0-90.3)$ \\
\hline
\end{tabular}

Primary group; ${ }^{* *} \mathrm{p}<0.01,{ }^{*} \mathrm{p}<0.05$. Coexisting group; ${ }^{*} \mathrm{p}<0.01{ }^{\dagger} \mathrm{p}<0.05$. 
Table 6. Cerebrovascular disease history in primary group.

\begin{tabular}{|c|c|c|c|c|}
\hline & \multicolumn{2}{|c|}{ Cerebrovascular disease history group $(n=47)$} & \multicolumn{2}{|c|}{ None group $(\mathrm{n}=24)$} \\
\hline & Death $(n=9)$ & Survival $(\mathrm{n}=38)$ & Death $(n=10)$ & Survival $(\mathrm{n}=14)$ \\
\hline $\begin{array}{l}\text { Volume of left pectoralis } \\
\text { major muscle }\left(\mathrm{mm}^{3}\right)\end{array}$ & $2886.8(1927.0-4232.1)^{*}$ & $4210.9(2713.2-6236.1)^{*}$ & $4252.5(1971.6-5324.6)$ & $4024.9(3074.9-7548.7)$ \\
\hline $\begin{array}{l}\text { Volume of right pectoralis } \\
\text { major muscle }\left(\mathrm{mm}^{3}\right)\end{array}$ & $2379.8(1689.5-4159.2)^{*}$ & $4542.7(2663.7-6579.4)^{*}$ & $4153.0(2180.5-5308.8)$ & $3801.8(3163.2-7198.7)$ \\
\hline $\begin{array}{l}\text { Thickness of left pectoralis } \\
\text { major muscle }(\mathrm{mm})\end{array}$ & $6.9(4.7-9.5)$ & $6.0(4.6-8.3)$ & $4.7(3.1-5.4)$ & $8.0(5.7-11.8)$ \\
\hline $\begin{array}{l}\text { Thickness of right pectoralis } \\
\text { major muscle }(\mathrm{mm})\end{array}$ & $5.9(3.6-9.3)$ & $7.4(4.9-8.7)$ & $4.6(3.9-6.9)$ & $7.8(6.3-12.3)$ \\
\hline $\begin{array}{l}\text { Cross-sectional area of left } \\
\text { rectus abdominis muscle } \\
\qquad\left(\mathrm{mm}^{2}\right)\end{array}$ & $233.6(109.4-327.9)$ & $232.6(133.0-331.0)$ & $179.2(50.6-216.27)^{\dagger}$ & $252.3(178.1-372.0)^{\dagger}$ \\
\hline $\begin{array}{l}\text { Cross-sectional area of right } \\
\text { rectus abdominis muscle } \\
\qquad\left(\mathrm{mm}^{2}\right)\end{array}$ & $199.3(77.0-283.9)$ & $185.6(131.3-349.4)$ & $118.6(46.1-201.8)^{\dagger}$ & $219.2(187.1-353.5)^{\dagger}$ \\
\hline $\begin{array}{l}\text { Thickness of left rectus } \\
\text { abdominis muscle (mm) }\end{array}$ & $4.0(2.5-8.7)$ & $5.9(3.9-9.2)$ & $4.6(3.8-6.8)^{\dagger}$ & $6.6(5.4-9.4)^{\dagger}$ \\
\hline $\begin{array}{l}\text { Thickness of right rectus } \\
\text { abdominis muscle (mm) }\end{array}$ & $5.3(3.4-8.7)$ & $6.9(4.6-8.8)$ & $5.8(3.8-6.5)$ & $7.8(6.2-9.8)$ \\
\hline $\begin{array}{l}\text { Cross-sectional area of left } \\
\text { psoas major muscle }\left(\mathrm{mm}^{2}\right)\end{array}$ & $317.7(244.1-456.6)$ & $409.0(251.5-617.7)$ & $452.5(349.7-547.7)$ & $469.3(346.5-491.1)$ \\
\hline $\begin{array}{l}\text { Cross-sectional area of right } \\
\text { psoas major muscle }\left(\mathrm{mm}^{2}\right)\end{array}$ & $446.3(294.5-544.8)$ & $436.5(259.7-623.9)$ & $414.4(292.1-620.0)$ & $497.9(383.4-564.9)$ \\
\hline Albumin level (g/dl) & $3.0(2.7-3.2)$ & $3.6(2.7-3.7)$ & $2.9(2.5-3.3)^{\dagger}$ & $3.6(3.0-3.9)^{\dagger}$ \\
\hline MNA-SF score & $4.0(2.0-5.0)$ & $5.0(3.0-7.0)$ & $3.5(3.0-4.3)^{\dagger}$ & $5.0(4.0-6.3)^{\dagger}$ \\
\hline FOIS score & $1.0(1.0-4.0)$ & $1.0(1.0-3.0)$ & $1.0(1.0-3.3)$ & $1.0(1.0-4.5)$ \\
\hline BI score & $0.0(0.0-0.0)$ & $0.0(0.0-0.0)$ & $0.0(0.0-37.5)$ & $0.0(0.0-6.3)$ \\
\hline Hospitalized days (day) & $13.5(4.3-48.5)$ & $26.0(13.0-50.0)$ & $50.5(16.0-73.5)$ & $27.5(8.5-38.5)$ \\
\hline Age (yr) & $88.0(86.5-90.5)^{\star}$ & $86.0(84.0-89.0)^{\star}$ & $83.5(78.5-90.0)$ & $86.0(75.0-91.8)$ \\
\hline
\end{tabular}

Cerebrovascular disease history group; ${ }^{\star} \mathrm{p}<0.05$ None group; ${ }^{\dagger} \mathrm{p}<0.05$.

cerebrovascular disease history group and the non-cerebrovascular disease history group, respectively. In the cerebrovascular disease history group, the volume of the pectoralis major muscle (left and right) was significantly larger, while age was significantly lower in patients who survived compared to those who did not. In the non-cerebrovascular disease history group, the thickness of the pectoralis major muscle (left and right) and the thickness of the left rectus abdominis muscle were significantly larger, whilst albumin levels and MNA-SF scores were significantly higher in patients who survived compared to those who did not.

4) Grouping by original disease in coexisting disease group

Table 7 shows the comparisons of variables between prognosis groups divided according to the original disease. Both the cerebrovascular disease group and the internal disease group showed significant differences in FOIS scores for patients who survived and those who did not. Additionally, in the orthopedic disease group, FOIS scores tended to have a higher median in patients who survived 
Table 7. Grouping by original disease in coexisting disease group.

\begin{tabular}{|c|c|c|c|c|c|c|}
\hline & \multicolumn{2}{|c|}{ Cerebrovascular disease $(n=40)$} & \multicolumn{2}{|c|}{ Internal disorders $(\mathrm{n}=14)$} & \multicolumn{2}{|c|}{ Orthopedic disease $(\mathrm{n}=12)$} \\
\hline & $\begin{array}{l}\text { Death } \\
(\mathrm{n}=6)\end{array}$ & $\begin{array}{l}\text { Survival } \\
(\mathrm{n}=34)\end{array}$ & $\begin{array}{l}\text { Death } \\
(\mathrm{n}=6)\end{array}$ & $\begin{array}{l}\text { Survival } \\
(\mathrm{n}=8)\end{array}$ & Death $(\mathrm{n}=1)$ & $\begin{array}{l}\text { Survival } \\
(\mathrm{n}=11)\end{array}$ \\
\hline $\begin{array}{l}\text { Volume of left pectoralis } \\
\text { major muscle }\left(\mathrm{mm}^{3}\right)\end{array}$ & $\begin{array}{c}5382.4 \\
(2837.2-15655.4)\end{array}$ & $\begin{array}{c}6370.1 \\
(4278.3-9568.2)\end{array}$ & $\begin{array}{c}4556.3 \\
(3617.0-6306.5)\end{array}$ & $\begin{array}{c}5841.8 \\
(3481.2-10732.5)\end{array}$ & 4254.6 & $\begin{array}{c}5611.7 \\
(3629.6-7881.9)\end{array}$ \\
\hline $\begin{array}{l}\text { Volume of right pectoralis } \\
\text { major muscle }\left(\mathrm{mm}^{3}\right)\end{array}$ & $\begin{array}{c}5505.4 \\
(3081.2-15320.2)\end{array}$ & $\begin{array}{c}6703.8 \\
(4011.8-8764.3)\end{array}$ & $\begin{array}{c}5056.0 \\
(3870.0-6259.8)\end{array}$ & $\begin{array}{c}5642.5 \\
(3311.7-11268.4)\end{array}$ & 5078.2 & $\begin{array}{c}4992.6 \\
(4393.3-8064.0)\end{array}$ \\
\hline $\begin{array}{l}\text { Thickness of left pectoralis } \\
\text { major muscle }(\mathrm{mm})\end{array}$ & $\begin{array}{c}7.1 \\
(3.4-9.5)\end{array}$ & $\begin{array}{c}8.0 \\
(5.8-10.8)\end{array}$ & $\begin{array}{c}4.0 \\
(3.3-7.5)\end{array}$ & $\begin{array}{c}6.5 \\
(5.9-7.1)\end{array}$ & 5.4 & $\begin{array}{c}6.9 \\
(5.0-8.1)\end{array}$ \\
\hline $\begin{array}{l}\text { Thickness of right pectoralis } \\
\text { major muscle }(\mathrm{mm})\end{array}$ & $\begin{array}{c}7.1 \\
(4.4-12.9)\end{array}$ & $\begin{array}{c}7.9 \\
(6.3-10.8)\end{array}$ & $\begin{array}{c}5.2 \\
(4.7-8.1)\end{array}$ & $\begin{array}{c}7.8 \\
(5.8-9.7)\end{array}$ & 8.9 & $\begin{array}{c}5.3 \\
(4.3-8.8)\end{array}$ \\
\hline $\begin{array}{l}\text { Cross-sectional area of left } \\
\text { rectus abdominis muscle }\left(\mathrm{mm}^{2}\right)\end{array}$ & $\begin{array}{c}307.0 \\
(174.3-461.7)\end{array}$ & $\begin{array}{c}222.7 \\
(151.5-311.2)\end{array}$ & $\begin{array}{c}193.8 \\
(134.4-368.5)\end{array}$ & $\begin{array}{c}248.6 \\
(115.9-413.2)\end{array}$ & 50.2 & $\begin{array}{c}195.3 \\
(148.4-284.8)\end{array}$ \\
\hline $\begin{array}{l}\text { Cross-sectional area of right } \\
\text { rectus abdominis muscle }\left(\mathrm{mm}^{2}\right)\end{array}$ & $\begin{array}{c}242.4 \\
(112.6-417.8)\end{array}$ & $\begin{array}{c}231.6 \\
(196.9-404.1)\end{array}$ & $\begin{array}{c}259.7 \\
(123.8-370.8)\end{array}$ & $\begin{array}{c}346.3 \\
(209.1-429.7)\end{array}$ & 41.8 & $\begin{array}{c}201.1 \\
(126.8-288.4)\end{array}$ \\
\hline $\begin{array}{l}\text { Thickness of left rectus } \\
\text { abdominis muscle (mm) }\end{array}$ & $\begin{array}{c}6.2 \\
(4.0-9.1)\end{array}$ & $\begin{array}{c}5.9 \\
(5.1-8.4)\end{array}$ & $\begin{array}{c}6.0 \\
(4.5-8.1)\end{array}$ & $\begin{array}{c}7.4 \\
(4.6-11.0)\end{array}$ & 1.0 & $\begin{array}{c}6.3 \\
(5.0-9.4)\end{array}$ \\
\hline $\begin{array}{l}\text { Thickness of right rectus } \\
\text { bdominis muscle (mm) }\end{array}$ & $\begin{array}{c}6.8 \\
(4.0-8.2)\end{array}$ & $\begin{array}{c}7.3 \\
(5.9-8.7)\end{array}$ & $\begin{array}{c}6.2 \\
(4.5-7.8)\end{array}$ & $\begin{array}{c}6.8 \\
(5.0-11.9)\end{array}$ & 1.4 & $\begin{array}{c}8.3 \\
(5.0-10.5)\end{array}$ \\
\hline $\begin{array}{l}\text { Cross-sectional area of left } \\
\text { psoas major muscle }\left(\mathrm{mm}^{2}\right)\end{array}$ & $\begin{array}{c}468.8 \\
(272.8-1206.1)\end{array}$ & $\begin{array}{c}522.5 \\
(337.1-758.3)\end{array}$ & $\begin{array}{c}472.0 \\
(292.6-676.7)\end{array}$ & $\begin{array}{c}463.3 \\
(412.7-715.6)\end{array}$ & 495.0 & $\begin{array}{c}500.1 \\
(388.1-845.6)\end{array}$ \\
\hline $\begin{array}{l}\text { Cross-sectional area of right } \\
\text { psoas major muscle }\left(\mathrm{mm}^{2}\right)\end{array}$ & $\begin{array}{c}515.2 \\
(247.9-1310.4)\end{array}$ & $\begin{array}{c}543.2 \\
(455.6-660.5)\end{array}$ & $\begin{array}{c}529.5 \\
(259.9-736.6)\end{array}$ & $\begin{array}{c}594.2 \\
(503.1-782.6)\end{array}$ & 564.9 & $\begin{array}{c}619.7 \\
(497.6-884.2)\end{array}$ \\
\hline Albumin level (g/dl) & $4.4(3.5-4.9)$ & $4.0(3.3-4.4)$ & $3.1(2.9-3.3)$ & $3.7(2.9-4.1)$ & 3.8 & $3.5(2.8-4.2)$ \\
\hline MNA-SF score & $7.0(6.0-8.0)$ & $7.0(5.8-8.3)$ & $5.5(3.8-6.5)$ & $7.0(4.3-9.5)$ & 4.0 & $6.0(4.0-6.0)$ \\
\hline FOIS score & $1.0(1.0-1.0)^{\star}$ & $4.0(1.0-5.0)^{*}$ & $2.5(1.0-4.3)^{\dagger}$ & $5.0(4.0-6.0)^{\dagger}$ & 1.0 & $4.0(4.0-5.0)$ \\
\hline BI score & $0.0(0.0-0.0)$ & $0.0(0.0-0.0)$ & $0.0(0.0-3.8)$ & $7.5(0.0-67.5)$ & 0.0 & $0.0(0.0-1.25)$ \\
\hline Hospitalized days (day) & $57.0(34.0-103.0)$ & $54.5(28.8-95.0)$ & $23.0(6.0-116.8)$ & $40.5(29.0-55.3)$ & 21 & $32.0(22.0-48.0)$ \\
\hline Age (yr) & $79.0(73.0-88.0)$ & $79.5(71.5-83.3)$ & $83.5(79.0-92.8)$ & $85.5(80.3-88.0)$ & 91.0 & $84.0(78.0-91.0)$ \\
\hline
\end{tabular}

Cerebrovascular disease group; ${ }^{*} \mathrm{p}<0.05$ Internal disorders group; ${ }^{\dagger} \mathrm{p}<0.05$.

compared to the one patient who died.

5) Forced entry multiple regression analysis

In the primary disease group, a regression equation of $\mathrm{Y}=-0.058-0.015 \mathrm{x} 1+$ $0.056 \times 2+0.124 \times 3+0.029 \times 4-0.009 \times 5$ (x1: thickness of the left pectoralis major muscle, $\mathrm{x} 2$ : thickness of the right pectoralis major muscle, $\mathrm{x} 3$ : albumin level, $\mathrm{x} 4$ : MNA-SF, x5: FOIS) was obtained. The thickness of the right pectoralis major muscle had a high influence on the dependent variables $(\mathrm{p}<0.05)$. In the coexisting disease group, a regression equation of $\mathrm{Y}=0.238+0.020 \times 1-0.012 \times 2+$ $0.033 \times 3-0.001 \times 4+0.100 \times 5$ was obtained. The FOIS scores had a high influence on the dependent variables $(\mathrm{p}<0.05)$.

\section{Discussion}

We investigated whether the capacity of the pectoralis major muscle and rectus abdominis muscle were prognostic factors for aspiration pneumonia. In all patients, prognosis was associated with the volume and thickness of the pectoralis major muscle (left and right), the thickness of the right rectus abdominis muscle, 
MNA-SF score, and FOIS score. In the primary disease group, the capacity of the pectoralis major muscle (volume and thickness) was the most relevant factor for prognosis, whereas FOIS score was most relevant in the coexisting disease group. Furthermore, between the primary and coexisting disease groups, there were significant differences in volume of the pectoralis major muscle (left and right), thickness of the left pectoralis major muscle, cross-sectional area of the psoas major muscle (left and right), nutritional status, swallowing function, number of days of hospitalization, and age. These results suggested the potential presence of sarcopenia in the primary disease group.

In this study, muscle mass and nutritional status were found to be related to prognosis in patients with aspiration pneumonia. Ebihara et al. [21] reported that the patient's cough power after aspiration is related to prognosis in patients with aspiration pneumonia. Moreover, in a previous study on prognosis of community-acquired pneumonia in the elderly, the variable most relevant to prognosis was nutritional status [22]. In the present study, prognosis in patients with aspiration pneumonia was related to the pectoralis major muscle and the rectus abdominis muscle, which are involved in cough and nutritional status. Potential sarcopenia in the primary disease group was prominent, especially since capacity of the pectoralis major muscle was most relevant to prognosis. For the psoas major muscle, a significant difference was observed between the primary and the coexisting disease groups, but a relationship with prognosis was not observed within all subjects, the primary disease group, or the coexisting disease group. These results suggest that the pectoralis major muscle may be a more suitable prognostic factor for aspiration pneumonia.

Muscle mass, nutritional status, swallowing function, number of days of hospitalization, and age were significantly different between the primary and coexisting disease groups. The greater number of days of hospitalization in the coexisting disease group was considered to be due to the occurrence of aspiration pneumonia during treatment for other diseases. However, the effects of potential sarcopenia in the primary disease group should also be considered. Wakabayashi et al. reported that $88 \%$ to $91 \%$ of patients with hospital-associated deconditioning were malnourished [23] [24]. Additional reports have described the association between low nutritional status and sarcopenia in the elderly [11] [25] [26] [27]. Sarcopenia develops from aging and malnutrition due to decreased swallowing function, resulting in decreased muscle mass and degeneration of muscle fibers, which are related to decrease coughing power [28]. Furthermore, presbyphagia [29] [30] [31], or age-related changes in swallowing function, may also have had an influence in the primary disease group. In the coexisting disease group, the FOIS score was the most relevant factor for prognosis. We suggest that many primary diseases can induce aspiration pneumonia. Our results showed that evaluation of swallowing function was the most important factor for prognosis in the coexisting disease group. Swallowing function was most related to prognosis in the analysis of each original disease within the coexisting disease 
group.

Thickness of the pectoralis major muscle was determined to be an independent factor for prognosis in the primary disease group. The percentage of domestic handedness in the Japanese population is $90.5 \%$ right-handed, $4.2 \%$ double dominant, and 5.3\% left-handed [32]. In our study, there were many right-handed patients, so handedness may have influenced the difference in pectoralis major muscle thickness. Moreover, with regard to sarcopenia in the primary disease group, it is suggested that decreased muscle capacity on the dominant side may have affected prognosis. However, we did not evaluate the difference in lateral muscle strength, including grip and arm strength. Further studies are needed to investigate the associations between lateral muscle strength, pectoralis major muscle volume, sarcopenia, and aspiration pneumonia in the elderly.

In primary disease group, notice to Sarcopenia and to improve malnutrition earlier is required. Our study suggests prophylaxis of sarcopenia before hospitalization leads to a good prognosis in aspiration pneumonia. In addition, in coexisting disease group, it should be noticed that swallowing function. It is suggested that early evaluation and training of swallowing function leads to a good prognosis. Furthermore, in elderly people, nutritional status was also evaluated; it is required to improve malnutrition if necessary.

Our study had several limitations. First, the sample size was small, and we did not perform physical examinations, such as skeletal muscle mass measurement, grip strength measurement, and the timed up and go test, which are required for diagnosis of sarcopenia [2] [3] [4] [33]. Moreover, respiratory function tests, such as blood gas analysis, are necessary to explain the association between respiratory function and thickness or volume of the pectoralis major muscle. Further studies are needed to clarify the associations between each additional variable and to perform comparisons of the studied variables between patients with aspiration pneumonia and healthy elderly subjects.

\section{Conclusion}

It is suggested that in elderly patients with aspiration pneumonia as the primary disease, the capacity of the pectoralis major muscle may predict prognosis. In addition, it is conceivable that in patients with aspiration pneumonia as a coexisting disease, swallowing function can be used to predict prognosis.

\section{Acknowledgements}

We would like to thank all our patients for their hospital. We are grateful to all parties at The Graduate School, Kyushu University of Health and Welfare for helpful discussions.

\section{Disclosure Statement}

The authors declare no conflicts of interest. 


\section{References}

[1] Rosenberg, I.H. (1989) Summary Comments. The American Journal of Clinical Nutrition, 50, 1231-1233.

[2] Muscaritoli, M., Anker, S.D., Argilés, J., Aversa, Z., Bauer, J.M., Biolo, G., Boirie, Y., Bosaeus, I., Cederholm, T., Costelli, P., Fearon, K.C., Laviano, A., Maggio, M., Rossi Fanelli, F., Schneider, S.M., Schols, A. and Sieber, C.C. (2010) Consensus Definition of Sarcopenia, Cachexia and Pre-Cachexia: Joint Document Elaborated by Special Interest Groups (SIG) "Cachexia-Anorexia in Chronic Wasting Diseases" and "Nutrition in Geriatrics”. Clinical Nutrition, 29, 154-159.

https://doi.org/10.1016/j.clnu.2009.12.004

[3] Cruz-Jentoft, A.J., Baeyens, J.P., Bauer, J.M., Boirie, Y., Cederholm, T., Landi, F., Martin, F.C., Michel, J.P., Rolland, Y., Schneider, S.M., Topinková, E., Vandewoude, M. and Zamboni, M. (2010) European Working Group on Sarcopenia in Older People. Sarcopenia: European Consensus on Definition and Diagnosis. Age Aging, 39, 412-423. https://doi.org/10.1093/ageing/afq034

[4] Fielding, R.A., Vellas, B., Evans, W.J., Bhasin, S., Morley, J.E., Newman, A.B., Kan, G.A., Andrieu, S., Bauer, J., Breuille, D., Cederholm, T., Chandler, J., Meynard, C.D., Donini, L., Harris, T., Kannt, A., Guibert, F.K., Onder, G., Papanicolaou, D., Rolland, Y., Rooks, D., Sieber, C., Souhami, E., Verlaam, S. and Zamboni, M. (2011) Sarcopenia: An Undiagnosed Condition in Older Adults. Current Consensus Definition: Prevalence, Etiology, and Consequences. International Working Group on Sarcopenia. Journal of the American Medical Directors Association, 12, 249-256. https://doi.org/10.1016/j.jamda.2011.01.003

[5] Wakabayashi, H., Sashika, H. and Matsushima, M. (2015) Head Lifting Strength Is Associated with Dysphagia and Malnutrition in Frail Older Adults. Geriatrics \& Gerontology International, 15, 410-416. https://doi.org/10.1111/ggi.12283

[6] Butler, S.G., Stuart, A., Leng, X., Wilhelm, E., Rees, C., Williamson, J. and Kritchevsky, S.B. (2011) The Relationship of Aspiration Status with Tongue and Handgrip Strength in Healthy Older Adults. The Journals of Gerontology. Series A, Biological Sciences and Medical Sciences, 66, 452-458. https://doi.org/10.1093/gerona/glq234

[7] Humbert, I.A. and Robbins, J. (2008) Dysphagia in the Elderly. Physical Medicine and Rehabilitation Clinics of North America, 19, 853-866.

https://doi.org/10.1016/j.pmr.2008.06.002

[8] Tamura, F., Kikutani, T., Tohara, T., Yoshida, M. and Yaegaki, K. (2012) Tongue Thickness Relates to Nutritional Status in the Elderly. Dysphagia, 27, 556-561. https://doi.org/10.1007/s00455-012-9407-Z

[9] Black, L.F. and Hyatt, R.E. (1969) Maximal Respiratory Pressures: Normal Values and Relationship to Age and Sex. The American Review of Respiratory Disease, 99, 696-702.

[10] Enright, P.L., Kronmal, R.A., Manolio, T.A., Schenker, M.B. and Hyatt R.E. (1994) Respiratory Muscle Strength in the Elderly. Correlates and Reference Values. Cardiovascular Health Study Research Group. ATS Journals, 149, 430-438.

[11] Kim, J., Davenport, P. and Sapienza, C. (2009) Effect of Expiratory Muscle Strength Training on Elderly Cough Function. Archives of Gerontology and Geriatrics, 48, 361-366.

[12] Krell, R.W., Kaul, D.R., Martin, A.R., Englesbe, M.J., Sonnenday, C.J., Cai, S. and Malani, P.N. (2013) Association between Sarcopenia and the Risk of Serious Infection among Adults Undergoing Liver Transplantation. Liver Transplantation, 19, 
1396-1402. https://doi.org/10.1002/lt.23752

[13] Dodson, R.M., Firoozmand, A., Hyder, O., Tacher, V., Cosgrove, D.P., Bhagat, N., Herman, J.M., Wolfgang, C.L., Geschwind, J.F., Kamel, I.R. and Pawlik, T.M. (2013) Impact of Sarcopenia on Outcomes Following Intra-Arterial Therapy of Hepatic Malignancies. Journal of Gastrointestinal Surgery, 17, 2123-2132. https://doi.org/10.1007/s11605-013-2348-5

[14] Mori, N., Higashiguchi, T., Ito, A., Futamura, A., Watanabe, T. and Ishikawa, A. (2014) Clinical Significance of the Cross-Sectional Area of the Psoas Major Muscle on a Computed Tomography Image in Cancer Patients. Journal of Japanese Society for Parenteral and Enteral Nutrition, 29, 1211-1217.

[15] Fairchild, B., Webb, T.P., Xiang, Q., Tarima, T. and Brasel, K.J. (2015) Sarcopenia and Frailty in Elderly Trauma Patients. World Journal of Surgery, 39, 373-379. https://doi.org/10.1007/s00268-014-2785-7

[16] Rubenstein, L.Z., Harker, J., Salva, A., Guigoz, Y. and Vellas, B. (2001) Screening for Undernutrition in Geriatric Practice: Developing the Short-Form Mini-Nutritional Assessment (MNA-SF). The Journals of Gerontology. Series A, Biological Sciences and Medical Sciences, 56, 366-372. https://doi.org/10.1093/gerona/56.6.M366

[17] Kuzuya, M., Kanda, S., Koike, T., Suzuki, Y., Satake, S. and Iguchi, A. (2005) Evaluation of Mini-Nutritional Assessment for Japanese Frail Elderly. Nutrition, 21, 489-503.

[18] Izawa, S., Kuzuya, M., Okada, K., Enoki, H., Koike, T., Kanda, S. and Iguchi, A. (2006) The Nutritional Status of Frail Elderly with Care Needs According to the Mini-Nutritional Assessment. Clinical Nutrition, 25, 962-967.

[19] Crary, M.A., Carnaby-Mann, G.D. and Groher, M.E. (2005) Initial Psychometric Assessment of a Functional Oral Intake Scale for Dysphagia in Stroke Patients. Archives of Physical Medicine and Rehabilitation, 86, 1516-1520.

[20] Mahoney, F.I. and Barthel, D. (1965) Functional Evaluation: The Barthel Index. Maryland State Medical Journal, 14, 61-65.

[21] Ebihara, S., Sekiya, H., Miyagi, M., Ebihara, T. and Okazaki, T. (2016) Dysphagia, Dystussia, and Aspiration Pneumonia in Elderly People. Journal of Thoracic Disease, 8, 632-639. https://doi.org/10.21037/jtd.2016.02.60

[22] Riquelme, R., Torres, A., El-Ebiary, M., Bellacasa, J.P., Estruch, R., Mensa, J., Fernández-Solá, J., Hernández, C. and Rodriguez-Roisin, R. (1996) Community-Acquired Pneumonia in the Elderly: A Multivariate Analysis of Risk and Prognostic Factors. American Journal of Respiratory and Critical Care Medicine, 154, 1450-1455. https://doi.org/10.1164/ajrccm.154.5.8912763

[23] Wakabayashi, H. and Sashika, H. (2011) Association of Nutrition Status and Rehabilitation Outcome in the Disuse Syndrome: A Retrospective Cohort Study. General Medicine, 12, 69-74. https://doi.org/10.14442/general.12.69

[24] Wakabayashi, H. and Sashika, H. (2014) Malnutrition Is Associated with Poor Rehabilitation Outcome in Elderly Inpatients with Hospital-Associated Deconditioning a Prospective Cohort Study. Journal of Rehabilitation Medicine, 46, 277-282. https://doi.org/10.2340/16501977-1258

[25] Morley, J.E., Argiles, J.M., Evans, W.J., Bhasin, S., Cella, D., Deutz, N.E., Doehner, W., Fearon, K.C., Ferrucci, L., Hellerstein, M.K., Kalantar-Zadeh, K., Lochs, H., MacDonald, N., Mulligan, K., Muscaritoli, M., Ponikowski, P., Posthauer, M.E., Rossi Fanelli, F.R., Schambelan, M., Schols, A.M., Schuster, M.W. and Anker, S.D. (2010) Society for Sarcopenia, Cachexia, and Wasting Disease: Nutritional Recommendations for the Management of Sarcopenia. Journal of the American Medical 
Directors Association, 11, 391-396.

[26] Bales, C.W. and Ritchie, C.S. (2002) Sarcopenia, Weight Loss, and Nutritional Frailty in the Elderly. Annual Review of Nutrition, 22, 309-323.

https://doi.org/10.1146/annurev.nutr.22.010402.102715

[27] Solerte, S.B., Gazzaruso, C., Bonacasa, R., Rondanelli, M., Zamboni, M., Basso, C., Locatelli, E., Schifino, N., Giustina, A. and Fioravanti, M. (2008) Nutritional Supplements with Oral Amino Acid Mixtures Increases Whole-Body Lean Mass and Insulin Sensitivity in Elderly Subjects with Sarcopenia. American Journal of Cardiology, 101, 69-77.

[28] Lowery, E.M., Brubaker, A.L., Kuhlmann, E. and Kovacs, E.J. (2013) The Aging Lung. Clinical Interventions in Aging, 8, 1489-1496.

[29] Wakabayashi, H. (2014) Presbyphagia and Sarcopenic Dysphagia: Association between Aging, Sarcopenia, and Deglutition Disorders. The Journal of Frailty \& Aging, 3, 97-103.

[30] Ney, D.M., Weiss, J.M., Kind, A.J. and Robbins, J. (2009) Senescent Swallowing: Impact, Strategies, and Interventions. Nutrition in Clinical Practice, 24, 395-413. https://doi.org/10.1177/0884533609332005

[31] Ginocchio, D., Borghi, E. and Schindler, A. (2009) Dysphagia Assessment in the Elderly. Nutrition \& Metabolism, 27, 9-15.

[32] Okubo, M., Suzuki, H. and Nicholls, M.E. (2014) A Japanese Version of the Flanders Handedness Questionnaire. Shinrigaku Kenkyu, 85, 474-481. (In Japanese) https://doi.org/10.4992/jjpsy.85.13235

[33] Morley, J.E., Abbatecola, A.M., Argiles, J.M., Baracos, V., Bauer, J., Bhasin, S., Cederholm, T., Coats, A.J., Cummings, S.R., Evans, W.J., Fearon, K., Ferrucci, L., Fielding, R.A., Guralnik, J.M., Harris, T.B., Inui, A., Kalantar-Zadeh, K., Kirwan, B.A., Mantovani, G., Muscaritoli, M., Newman, A.B., Rossi-Fanelli, F., Rosano, G.M., Roubenoff, R., Schambelan, M., Sokol, G.H., Storer, T.W., Vellas, B., von Haehling, S., Yeh, S.S. and Anker, S.D. (2011) Society on Sarcopenia, Cachexia, and Wasting Disorders Trialist Workshop: Sarcopenia with Limited Mobility: An International Consensus. Journal of the American Medical Directors Association, 12, 403-409. 